\title{
VIOLÊNCIA CONTRA A MULHER EM SÃO JOSÉ DOS CAMPOS: ESTATÍSTICAS ALARMANTES CONTRA A DIGNIDADE DAS JOSEENSES
}

\author{
Alexandre José Reifschneider Ribeiro Coelho' \\ Celso Regis Romani² \\ Francisco Fernandes de Oliveira ${ }^{3}$ \\ Gabrielle Rossi Giannaccini ${ }^{4}$ \\ Giulia Gabriele Lazari Matos ${ }^{5}$ \\ Daniel Lipparelli Fernandez ${ }^{6}$ \\ Mauricio Martins Alves ${ }^{7}$ \\ Luiz Carlos A. de Aquino ${ }^{8}$
}

Resumo: Tomando como referência dados estatísticos registrados no site da SECRETARIA de Segurança Pública (www.ssp.sp.gov.br/novaestatistica/Mapas.aspx) e partindo da fundamentação em literatura especializada sobre o tema violência contra mulheres (artigos científicos); informações divulgadas pelos meios de comunicação (notícias, reportagens); depoimentos e vivências compartilhadas em espaços públicos virtuais (blogs) percebemos que o preconceito, a discriminação e a desigualdade, faces perversas da violência contra a mulher, colaboram para a permanência da violência mesmo após o advento da Lei 11.340 de 07 de Agosto de 2006, conhecida como Lei "Maria da Penha". Mostramos esta permanência da violência tendo como objeto de análise os crimes de estupro, lesão corporal e tentativa de homicídio, compreendidos no período de 2011 a 2015, subdivididos em Estado de São Paulo (Capital e Interior) e município de São José dos Campos.

Palavras-chave: Violência; Mulher; Lei Maria da Penha.

\footnotetext{
${ }_{1}^{1}$ Direito/Univap, Brasil. E-mail: acoelho@gmail.com.

2 Direito/Univap, Brasil. E-mail: celsoregisromani@gmail.com.

${ }^{3}$ Direito/Univap, Brasil. E-mail: fernando3103@yahoo.com.br.

${ }^{4}$ Direito/Univap, Brasil. E-mail: gabs_rg@hotmail.com.

${ }_{5}^{5}$ Direito/Univap, Brasil. E-mail: giulialazari@outlook.com.

${ }^{6}$ Direito/Univap, Brasil. E-mail: fernandez@univap.br.

${ }^{7}$ Direito/Univap, Brasil. E-mail: mmalves@univap.br.

${ }^{8}$ Direito/Univap, Brasil. E-mail: aquino@univap.br.
} 